\title{
VARIABILIDADE ESPACIAL E TEMPORAL DO TEOR DE ÁGUA DO SOLO SOB DUAS FORMAS DE USO $\left({ }^{1}\right)$
}

\author{
SIDNEY ROSA VIEIRA $\left({ }^{2 *}\right)$; MIGUEL ANGEL GONZÁLEZ GARCIA $\left({ }^{3}\right)$; \\ ANTONIO PAZ GONZÁLEZ $\left({ }^{4}\right)$; GLÉCIO MACHADO SIQUEIRA $\left({ }^{3,5}\right)$
}

\begin{abstract}
RESUMO
O objetivo deste trabalho foi analisar a variabilidade espacial do teor de água do solo, ao longo do tempo, em duas condições distintas de uso. Para tanto, foram efetuadas medições do teor de água no solo em área com vegetação natural e outra cultivada com culturas anuais em Galícia, Espanha. O solo foi classificado como Umbrisol (FAO) e as medições foram tomadas em uma parcela plana de $190 \mathrm{~m}^{2}$, da qual metade foi mantida com vegetação natural e metade cultivada com culturas anuais. As medições do teor de água foram efetuadas utilizando o aparelho TDR (Time Domain Reflectometry) a $15 \mathrm{~cm}$ de profundidade em 29/10/1993, 16/3/1994 e 13/10/1994 em um reticulado quadrado de $1 \mathrm{~m}$, compreendendo aproximadamente 100 pontos na parcela com vegetação natural e 90 pontos na parcela cultivada. A variabilidade espacial foi avaliada com uso de geoestatística, examinando semivariogramas, e efetuando interpolação por meio da técnica de krigagem para construção de mapas de isolinhas, a fim de examinar a estabilidade temporal dos locais com ocorrência de valores médios. Conclui-se que o cultivo e a cobertura do solo afetam a dependência espacial do teor de água uma vez que na parcela cultivada a dependência tende a desaparecer à medida que o conteúdo de água aumenta. Para a parcela sob vegetação natural ocorreu o contrário, com dependência espacial em distâncias maiores para a situação em que o conteúdo de água médio foi maior. A estabilidade temporal do teor de água do solo foi maior nos dias em que a dependència espacial entre amostras foi menor.
\end{abstract}

Palavras-chave: umidade do solo, TDR, geoestatística, Umbrisol.

\section{ABSTRACT \\ SPATIAL AND TEMPORAL VARIABILITY OF SOIL WATER CONTENT IN TWO LAND USES}

The objective of this study was to assess the spatial variability for soil water content as a function of time, in two distinct land uses. In order to do that, soil moisture measurements were taken in two adjacent plots, one of which was cultivated and the other was kept with natural vegetation, in Galicia, Spain. The water content was measured using a TDR at $15 \mathrm{~cm}$ depth. The soil was classified as an Umbrisol (FAO) and measurements were taken on a regular square grid of $1 \mathrm{~m}$ on a flat $190 \mathrm{~m}^{2}$ plot, half of which was cultivated and comprised 100 sampling points and the other half was with natural vegetation and comprised 90 samplings points. Dates of sampling were 29/October/1993, 16/March/1994 and 13/October/1994. The spatial variability was analyzed by the semivariograms, and by kriging estimation maps for each date and land use, and assessing temporal stability of the places where values close to the mean value occur. It was concluded that cultivation and cover crop affect the spatial dependence for soil water content since on the cultivated plot the spatial dependence tended to disappear as the water content increased. The reverse was found for the natural vegetation plot since it showed spatial dependence for larger distances as the water content increased. The time stability of soil water content was higher when spatial dependence among samples was lower.

Key words: Soil moisture, TDR, geostatistics, Umbrisol.

$\left({ }^{1}\right)$ Recebido para publicação em 24 de julho de 2007 e aceito em 19 de novembro de 2009.

$\left({ }^{2}\right)$ Instituto Agronômico, Centro de Pesquisa e Desenvolvimento de Solos e Recursos Ambientais, Caixa Postal 28, 13001-970 Campinas (SP), Brasil. Com bolsa do CNPq. $\left({ }^{*}\right)$ Autor correspondente. E-mail: sidney@iac.sp.gov.br.

$\left({ }^{3}\right)$ Universidad de Santiago da Compostela, 27002, Lugo, Espanha. E-mail: magonz@lugo.usc.es; glecio.machado@rai.usc.es

$\left({ }^{4}\right)$ Universidad de La Coruña, A Zapateira, 15071, La Coruña, Espanha. E-mail: tucho@udc.es

$\left({ }^{5}\right)$ Bolsista MAEC-AECI. 


\section{INTRODUÇÃO}

A água é uma das substâncias mais importantes para a vida na terra. Nas plantas, a água participa de muitas reações químicas importantes, e é responsável também pelo seu crescimento por meio da elongação celular atuando diretamente sobre a produção das culturas (MACHADO et al., 2006).

O solo, por sua vez, equipara-se como um grande reservatório de água, armazenada nos períodos chuvosos. O manejo adequado do solo deve almejar a maximização de sua capacidade em permitir a infiltração da água e seu armazenamento (MusY E Soutter, 1991). O manejo adequado do solo também deve garantir condições físícas para o desenvolvimento das raízes, sem a presença de camadas de compactadas (Dематте̂, 2004), que favorecem o encharcamento temporário, reduzem a quantidade de água infiltrada, interferindo na variabilidade espacial do teor de água no solo.

A variabilidade espacial do teor de água no solo é conseqüência de vários fatores, entre os quais, variações na textura e estrutura do solo, topografia, face de exposição ao sol e posição no relevo (McBratney, 1992). Uma das condições básicas para que a produção agrícola tenha competitividade em termos de rendimento, é que não haja limitações no fornecimento de água para as culturas; o conhecimento da distribuição espacial do conteúdo de água do solo é importante.

Segundo VACHAUd et al. (1985), a distribuição espacial do conteúdo de água no solo pode ter estabilidade temporal. Gonçalves et al. (1999), analisando a variabilidade espacial de teor de água no solo, concluíram que o padrão de variabilidade é estável no tempo. Se esse fato realmente ocorrer então é possível delimitar lugares no campo onde ocorrem sempre valores médios. Com base nesta hipótese, é possível que a variabilidade espacial de uma determinada medida em diferentes situações seja estável, o que pode ser verificado examinando-se semivariogramas escalonados, conforme descrito por VIEIRA et al. (1991).

VIEIRA et al. (1997) observaram que os semivariogramas podem ser escalonados para diferentes datas de amostragens e seus gráficos exibirão comportamentos semelhantes entre si. Portanto, com diferentes amostragens para teor de água no solo é possível a utilização e o ajuste de um único modelo para vários semivariogramas escalonados. Esta idéia expande a proposta de VACHAUD et al. (1985) pela qual, se a estabilidade temporal do semivariograma existir, não só ocorrerão valores médios aproximadamente nos mesmos lugares, como também todos os valores de teor de água decrescerão ou aumentarão em proporções aproximadamente constantes. Também já foi relatado por VIEIRA et al. (1996) que este fato, provavelmente, só ocorrerá durante a fase do processo evaporativo controlada pela demanda atmosférica. Neste caso, assim que a evaporação de água no solo passar a ser controlada pela condutividade hidráulica, na variabilidade espacial do teor de água no solo poderá ocorrer alterações e a hipótese de estabilidade temporal da distribuição de frequências como foi proposta por VACHAUD et al. (1985) poderá não ser mais válida. Nesta fase, pode ser importante o conhecimento de outras variáveis que podem afetar a distribuição espacial de água no solo, como por exemplo, textura e estrutura da camada superficial do solo.

O objetivo deste trabalho foi analisar a variabilidade espacial do teor de água do solo, ao longo do tempo, em duas condições distintas de uso.

\section{MATERIAL E MÉTODOS}

O experimento foi realizado em Castro de

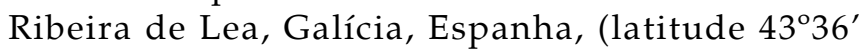
e longitude $7^{\circ} 27^{\prime}$ e altitude de $483 \mathrm{~m}$ ). O estudo foi realizado em duas áreas adjacentes, sendo uma cultivada com milho medindo $10 \times 9 \mathrm{~m}$, e outra com vegetação natural medindo $10 \times 10 \mathrm{~m}$, segundo esquema mostrado na figura 1 . Foram realizadas amostragens do teor de água no solo por meio da técnica de reflectrometria de domínio do tempo TDR (Topp e DAvis, 1985), a 0,15 m de profundidade, em espaçamento regular quadrado de $1 \mathrm{~m}$, em 29/10/ 1993,16/3/1994 e 13/10/1994. Dessa maneira, a parcela com vegetação natural tinha cem pontos de amostragem enquanto a parcela cultivada tinha 90 pontos. A parcela cultivada vem sendo manejada com preparo convencional e plantada com milho no verão e pastagem semeada (alfafa) no inverno durante os últimos cem anos, conforme relatado por González Garcia (1998). Em outubro/1993 e outubro/1994, esta parcela esteve em pousio, após a colheita de milho e semeada posteriormente com pastagem, quando foi feita a amostragem após a semeadura. A parcela com vegetação natural é composta de pequenos arbustos, na maioria pinus com alguma vegetação rasteira, predominando gramíneas.

O solo da área possui um horizonte superficial orgânico e ácido, chamado horizonte úmbrico, classificado como Umbrisol pelo sistema FAO (1998). PAZ GonZÁlez et al. (2000) descreveram a composição granulométrica média para as parcelas em estudo (Tabela 1) para a fração do solo menor que $2,0 \mathrm{~mm}$. 
Tabela 1. Composição granulométrica do solo para as duas condições de uso

\begin{tabular}{lcccc}
\hline Solo & Areia & Silte & Argila & Cascalho \\
\cline { 2 - 5 } & & & & $\mathrm{g} \mathrm{kg}^{-1}$ \\
\cline { 2 - 5 } Vegetação natural & 579,8 & 271,4 & 148,8 & 253,3 \\
Cultivado & 581,7 & 245,5 & 172,8 & 388,1 \\
\hline
\end{tabular}

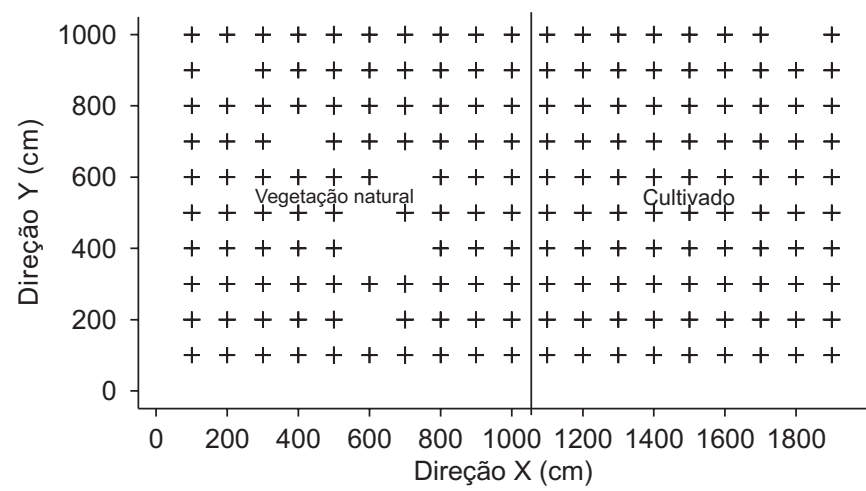

Figura 1. Esquema de amostragem para as duas parcelas experimentais.

Os principais momentos estatísticos foram determinados com a finalidade de examinar parâmetros de tendência central e de dispersão (VIEIRA et al., 2002). Para verificar se os dados seguem a distribuição normal de frequência, podese examinar os valores dos coeficientes de assimetria e de curtose, pois valores próximos a 0 e 3 são indicativos da presença de população amostral com distribuição normal. A correlação linear entre todas as combinações de pares de variáveis foi analisada, separadamente para cada local, sobretudo para revelar possíveis relacionamentos entre as variáveis.

A estabilidade temporal da distribuição de freqüência do teor de água pode ser monitorada mapeando-se a localização espacial das médias dos valores de diferentes amostragens. Para tanto, estabeleceu-se um limite em torno do valor médio (por exemplo $10 \%$ ), e em seguida contou-se o número de locais onde ocorreram valores entre o valor médio + / - o limite estabelecido. Quanto maior for esse número, maior o número de valores parecidos com a média ao longo do campo. Esse procedimento, porém, é bastante dependente da uniformidade dos dados em relação ao valor médio ou seja, quanto menor o coeficiente de variação maior será o número de locais onde ocorrerão a média +/- o limite estabelecido. Assim, a escolha do valor para o limite deverá ser orientada pelo valor do coeficiente de variação.

Uma vez que esse procedimento foi satisfeito, pode-se examinar a quantidade de locais que estão dentro do limite estabelecido e que permaneceram no limite entre as diferentes datas de amostragem. Esse número, mesmo sendo ligeiramente dependente do valor estabelecido para o limite em torno do valor médio, foi considerado como medida bastante clara da ocorrência destes valores nos mesmo locais em diferentes amostragens, ou seja, expressou a estabilidade temporal do teor de água.

A variabilidade espacial foi analisada por meio de semivariogramas, de acordo com VIEIRA et al. (1983). O semivariograma, $\gamma(h)$, de uma variável distribuída espacialmente, $z\left(x_{i}\right)$, é calculado conforme a Equação 1:

$$
\gamma(h)=\frac{1}{2 N(h)} \sum_{i=1}^{N(h)}\left[z\left(x_{i}\right)-z\left(x_{i}+h\right)\right]^{2}
$$

Em que: $N(h)$ é o número de observações separadas por uma distância $h$. Os semivariogramas foram ajustados a um modelo matemático de acordo com os seguintes parâmetros: efeito pepita $\left(C_{0}\right)$, patamar $\left(C_{0}+C_{1}\right)$, e alcance (a). A Equação 1 foi determinada considerando a hipótese intrínseca da geoestatística, dentro da qual não há nenhuma exigência para a existência de uma variância finita, $\operatorname{Var}(z)$. Exige-se apenas a estacionaridade da média e a estacionaridade de segunda ordem das diferenças $[(z(x)-z(x+h)]$ (Journel e Huijbregts, 1978). O comportamento do semivariograma para valores pequenos de $h$ revela aspectos muito importantes da variabilidade espacial das propriedades em estudo os quais podem ser utilizados para comparação.

Os semivariogramas para o teor de água no solo medido em diferentes datas foram escalonados, de acordo com VIEIRA et al. (1997):

$$
\gamma^{\mathrm{sc}}(\mathrm{h})=\frac{\gamma(\mathrm{h})}{\operatorname{Var}(\mathrm{z})}
$$

Em que: $\gamma^{s c}(h)$ é o semivariograma escalonado, $\gamma(h)$ é o semivariograma original, e $\operatorname{Var}(z)$ é a variância dos dados. Teoricamente, esta equação requer a existência de uma variância finita, a qual pode ser garantida se a estacionaridade de segunda ordem existir. Entretanto, a grandeza que se utiliza neste cálculo é apenas o número convenientemente calculado para variância dos dados, mas não exatamente a grandeza estatística variância. 
O escalonamento é utilizado com a finalidade de desenhar vários semivariogramas no mesmo gráfico, quando de outra maneira teriam escalas diferentes no eixo das semivariâncias. Quando semivariogramas escalonados se agrupam, pode-se dizer que as propriedades envolvidas têm variabilidade espacial semelhante (VieIra et al., 1997).

Os semivariogramas foram ajustados ao modelo esférico (Equação 3) identificado nas figuras como: $\operatorname{Esf}\left(\mathrm{C}_{0}, \mathrm{C}_{1}, \mathrm{a}\right)$, cuja equação de ajuste é:

$$
\begin{aligned}
& \gamma(\mathrm{h})=\mathrm{C}_{0}+\mathrm{C}_{1}\left[\frac{3}{2} \frac{\mathrm{h}}{\mathrm{a}}-\frac{1}{2}\left(\frac{\mathrm{h}}{\mathrm{a}}\right)^{3}\right], \text { para } \mathrm{h}<\mathrm{a} \\
& \gamma(\mathrm{h})=\mathrm{C}_{0}+\mathrm{C}_{1}, \text { para } \mathrm{h} \geq \mathrm{a}
\end{aligned}
$$

e ao modelo exponencial (Equação 4) identificado nas figuras como $\operatorname{Exp}\left(C_{0}, C_{1}, a\right)$, cuja equação de ajuste é:

$$
\gamma(h)=C_{0}+C_{1}\left[1-\operatorname{Exp}\left(-3 * \frac{h}{a}\right)\right]
$$

A técnica de interpolação por krigagem foi utilizada antes da construção de mapas, a fim de providenciar uma quantidade suficiente de informações e, assim, evitar estimativas de má qualidade e confiança. Mapas irreais podem ser obtidos quando são construídos usando-se apenas valores medidos e quando as estimativas são efetuadas por métodos que não respeitam as condições de estimativa sem viés e com variância mínima, segundo relataram Vieira et al., (1981). A construção dos mapas de isolinhas da variabilidade espacial para os atributos analisados foi feita usando o software SURFER 7.0 (Golden Software, 1999), cujos valores foram determinados para os locais não amostrados pela técnica de krigagem, segundo VieIRA (2000).

\section{RESULTADOS E DISCUSSÃO}

Os parâmetros estatísticos para o teor de água no solo para as três datas de amostragem e nas duas parcelas estão apresentados na tabela 2 . Em alguns pontos, o teor de água é nulo, fato que pode ocorrer caso o contato das hastes de TDR com o solo seja deficiente (Topp e DAvis, 1985). Esses pontos foram desconsiderados das análises. Com exceção dos dados coletados em 16/3/94, os valores médios indicaram que o solo estava mais úmido e mais uniforme na parcela cultivada do que na parcela sob vegetação natural. Considerando que nesta época (outubro) é o começo do outono em Galícia e que a parcela cultivada estava em pousio após a colheita de milho, consequentemente a vegetação natural retirou mais água do solo do que as ervas daninhas que ocorreram naturalmente na parcela cultivada. Além disso, os maiores valores de coeficiente de variação na parcela sob vegetação natural nas diferentes datas de amostragem indicam que o conteúdo de água no solo depende da distribuição espacial e do consumo de água pela vegetação ali presente.

Em 16/3/94, o teor de água estava ligeiramente menor na parcela cultivada, devido ao fato de ser fim do inverno e nessa parcela já havia sido semeada pastagem, ocasionando valores ligeiramente menores do teor de água quando comparada com a parcela com vegetação natural. A presença de valores de coeficiente de variação menores para a parcela cultivada está relacionada com a uniformização do solo durante as operações de preparo. TABOADA CASTRO et al., (1996), trabalhando com atributos químicos nas mesmas parcelas constataram coeficientes de variação muito maiores na parcela sob vegetação natural do que na parcela

\begin{tabular}{|c|c|c|c|c|c|c|c|c|}
\hline Data & $\mathrm{n}$ & Média & Variância & C.V. & Mínimo & Máximo & Assimetria & Curtose \\
\hline & \multicolumn{8}{|c|}{ Vegetação natural } \\
\hline $29 / 10 / 93$ & 100 & 22,86 & 53,10 & 31,9 & 3,10 & 35,80 & $-0,285$ & 2,552 \\
\hline $16 / 03 / 94$ & 95 & 37,35 & 59,37 & 20,6 & 17,30 & 55,20 & $-0,245$ & 3,074 \\
\hline \multirow[t]{2}{*}{$13 / 10 / 94$} & 93 & 12,95 & 17,69 & 32,5 & 3,90 & 24,70 & 0,269 & 2,804 \\
\hline & \multicolumn{8}{|c|}{ Cultivado } \\
\hline $29 / 10 / 93$ & 89 & 30,24 & 15,20 & 12,9 & 19,40 & 41,90 & 0,009 & 2,980 \\
\hline $16 / 03 / 94$ & 86 & 36,47 & 5,67 & 6,53 & 30,40 & 43,50 & $-0,035$ & 3,550 \\
\hline $13 / 10 / 94$ & 89 & 18,61 & 29,16 & 29,0 & 8,10 & 27,90 & $-0,219$ & 1,801 \\
\hline
\end{tabular}
cultivada.

Tabela 2. Parâmetros estatísticos para teor de água do solo (\%) nas duas condições de uso e nas três datas amostradas

n: número de amostras; C.V.: coeficiente de variação. 
Para as amostragens realizadas em 13/10/94 na parcela cultivada e em 29/10/93 e 13/10/94 na parcela com vegetação, é possível que tenha havido algum problema com o equipamento TDR utilizado, devido aos valores mínimos excessivamente baixos. Um fato bastante notável nesses dados é que, na parcela com vegetação natural, na medida em que o teor de água diminuiu, a variância também diminuiu, ao passo que, para a parcela cultivada ocorreu o contrário, ou seja, à medida que o teor de água diminuiu a variância aumentou (Figura 2). Para a parcela sob vegetação natural, é possível que a vegetação intercepte a precipitação pluvial e altere a distribuição espacial das gotas de chuvas e consequentemente do teor de água do solo. $\mathrm{O}$ aumento dos valores de variância à medida que os valores médios do teor de água diminuíram na parcela cultivada pode ter sido causado pela variabilidade na textura e/ou estrutura da superfície do solo, segundo relatado por PAZ GonZÁlez et al., (2000) para esta mesma parcela.

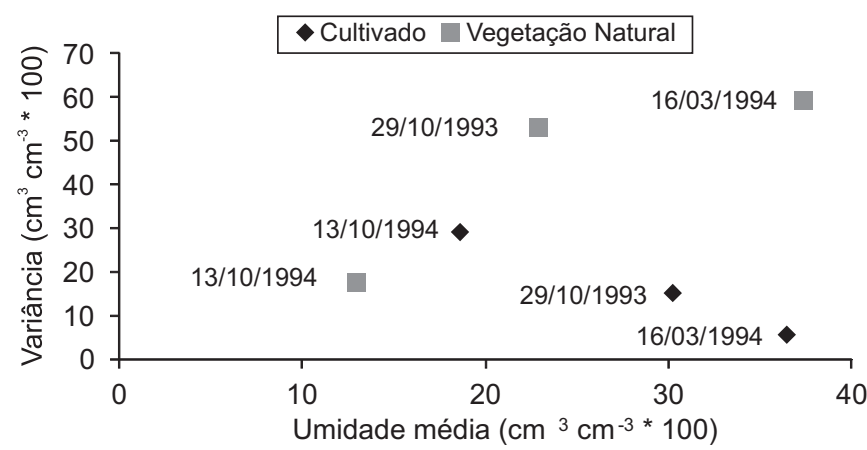

Figura 2. Relação entre a média e a variância do teor de água nas diferentes datas de amostragem. Cada símbolo representa a média do número de valores indicados na 2. ${ }^{\text {a }}$ coluna da tabela 2 para as datas de amostragem correspondentes.

Na tabela 3 são apresentados os resultados de estabilidade temporal dos valores médios de teor de água no solo nas duas parcelas estudadas. É importante notar que existe uma diferença de comportamento bastante grande com respeito à porcentagem de valores que estão dentro dos limites estabelecidos nas diferentes datas de amostragem. A presença de valores elevados do teor médio de água no solo $(36,47 \%$ para o solo cultivado e $37,35 \%$ para o solo com vegetação natural) sugere que a porcentagem de valores que estão dentro dos limites estabelecidos seja maior para a parcela sobre o solo cultivado do que para a parcela com vegetação natural. Entretanto, há que se considerar que esse fato ocorreu na amostragem efetuada em 16/3/94, ou seja no fim do inverno e além disso, quando a parcela cultivada havia sido preparada e semeada com pastagem. Por outro lado, na amostragem de 13/10/ 94 ocorreu o contrário, ou seja, a porcentagem de valores dentro da banda foi muito maior na parcela sob vegetação natural para teor de água muito menores $(12,95 \%)$ do que naquelas para a parcela sob cultivo $(18,61 \%)$. Para a amostragem realizada no outono (29/10/93), essa tendência não se confirmou.

O número de locais dentro dos limites especificados e coincidentes entre duas datas de amostragem, de modo geral, foi muito maior para a parcela sob cultivo (48) do que para aquela sob vegetação natural (24). Esse fato pode indicar que a parcela sob cultivo, de alguma maneira, possui maior uniformidade do que a parcela sob vegetação natural. Essa ocorrência, ainda, é mais significativa para as amostragens realizadas em 16/3/94 em que, mesmo com teor médio de água apenas ligeiramente maior para a parcela sob vegetação natural $(37,35 \%)$, o número de locais que coincidiram dentro dos limites estabelecidos foi quase três vezes maior na parcela sob cultivo ( 8 e 3 valores coincidentes, respectivamente, para a parcela com cultivo e com vegetação natural). Para este solo, então, a estabilidade temporal da distribuição espacial do teor de água no solo dependeu do seu uso com cultivo ou com vegetação natural.

Tabela 3. Estabilidade temporal de locais de ocorrência do teor médio de água nas duas condições de uso

\begin{tabular}{|c|c|c|c|c|c|c|c|}
\hline Data & Teor de médio de água & $\mathrm{A}$ & $\%$ & SQD & Pares de Datas & B & Intervalo \\
\hline & & & & & & & dias \\
\hline & \multicolumn{7}{|c|}{ Vegetação Natural } \\
\hline $29 / 10 / 1993$ & 22,86 & 20 & 20,0 & 13,002 & $29 / 10 / 93-16 / 03 / 94$ & 10 & 139 \\
\hline $16 / 03 / 1994$ & 37,35 & 45 & 47,4 & 17,556 & $29 / 10 / 93-13 / 10 / 94$ & 3 & 349 \\
\hline \multirow[t]{2}{*}{$13 / 10 / 1994$} & 12,95 & 24 & 25,8 & 0,8286 & $16 / 03 / 94-13 / 10 / 94$ & 14 & 240 \\
\hline & \multicolumn{7}{|c|}{ Cultivado } \\
\hline $29 / 10 / 1993$ & 30,24 & 48 & 51,6 & 17,419 & $29 / 10 / 93-16 / 03 / 94$ & 36 & 139 \\
\hline $16 / 03 / 1994$ & 36,47 & 78 & 90,7 & 17,787 & $29 / 10 / 93-13 / 10 / 94$ & 8 & 349 \\
\hline $13 / 10 / 1994$ & 18,61 & 16 & 17,9 & 0,9090 & $16 / 03 / 94-13 / 10 / 94$ & 14 & 240 \\
\hline
\end{tabular}

A: número de locais onde ocorreu o valor da média +/- o limite de 10\%; \%: porcentagem em relação ao número total de locais; SQD: soma dos quadrados dos desvios da média; B: número de locais coincidentes de ocorrência da média entre as duas datas. 
O número de locais coincidentes entre as diferentes datas de amostragem (Tabela 3), foi utilizado para o estudo da estabilidade temporal do conteúdo de água no solo. Aparentemente, existe uma proporcionalidade entre as porcentagens de pontos que caíram dentro dos limites especificados e os valores médios do conteúdo de água no solo (Figura 3). A relação entre o teor médio de água e a porcentagem de valores dentro dos limites especificados é, de algum modo, dependente do uso do solo. Para o solo sob vegetação natural, a porcentagem de valores dentro da banda especificada cresce ligeiramente com o teor de água no solo, porém, menos pronunciadamente quando comparado com a parcela cultivada, onde há um crescimento bastante pronunciado na porcentagem de valores dentro da banda especificada.

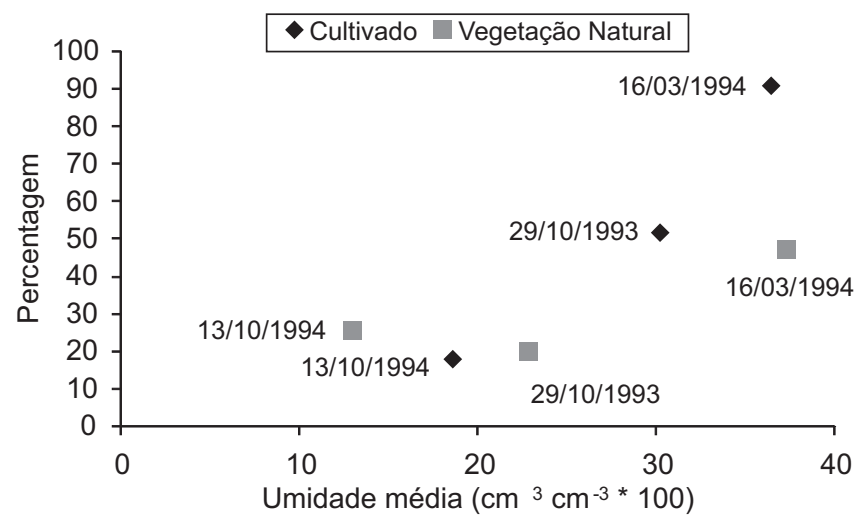

Figura 3. Relação entre o teor de médio de água e a porcentagem de valores dentro da banda estabelecida. Cada símbolo representa a média do número de valores indicados na 2. ${ }^{\text {a }}$ coluna da tabela 2 para as datas de amostragem correspondentes.

Os resultados apresentados na figura 3 demonstram que os ciclos de umidecimento e de secamento do solo ao longo do tempo para a área de estudo variaram no espaço. Este resultado contraria a proposta de VACHAUD et al., (1985), demonstrando que a distribuição espacial do conteúdo de água no solo não é estável no tempo, pelo menos dentro do período amostrado e para as condições da área de estudo. Além disso, é possível que esse resultado seja afetado por outros fatores como o estágio de desenvolvimento da vegetação de cobertura e época do ano. Com respeito à época do ano, também é importante considerar que as amostragens foram efetuadas em três épocas ao longo de um ano. Timm et al. (2006) constataram resultados semelhantes estudando a variabilidade espacial e temporal do conteúdo de água no solo e descrevem que, em períodos úmidos, não há modificações no padrão espacial da umidade do solo, enquanto para o período seco o contrário é observado. Esses padrões podem ser associados a eventos de precipitação pluvial, alterando a estrutura de correlação espacial do conteúdo de água no solo. Todavia, também é preciso considerar as variações espaciais de características do solo em termos de textura, estrutura e cobertura vegetal, que também exercem importante papel na dinâmica da água no solo e na possível manutenção da estabilidade temporal.

$\mathrm{Na}$ figura 4, estão descritos os semivariogramas para as amostragens efetuadas nas duas parcelas de estudos e nas três datas de amostragem. Nota-se que o teor de água para 13/10/ 94 revelou dependência espacial forte. Por outro lado, os teores de água em 29/10/93 e 16/3/94 tiveram semivariogramas que identificam baixa dependência espacial, fato constatado pelos maiores valores de efeito pepita $\left(C_{0}\right)$, uma vez que este atributo representa a variabilidade não detectada durante o processo de amostragem (VIEIRA, 2000). Em 13/10/94, a parcela cultivada tinha o menor valor médio para teor de água e também o maior coeficiente de variação. Além disso, estes foram os únicos teores de água que não tiveram distribuição de frequência normal (Tabela 2), uma vez que não houve valores de assimetria e curtose próximos a 0 e 3.
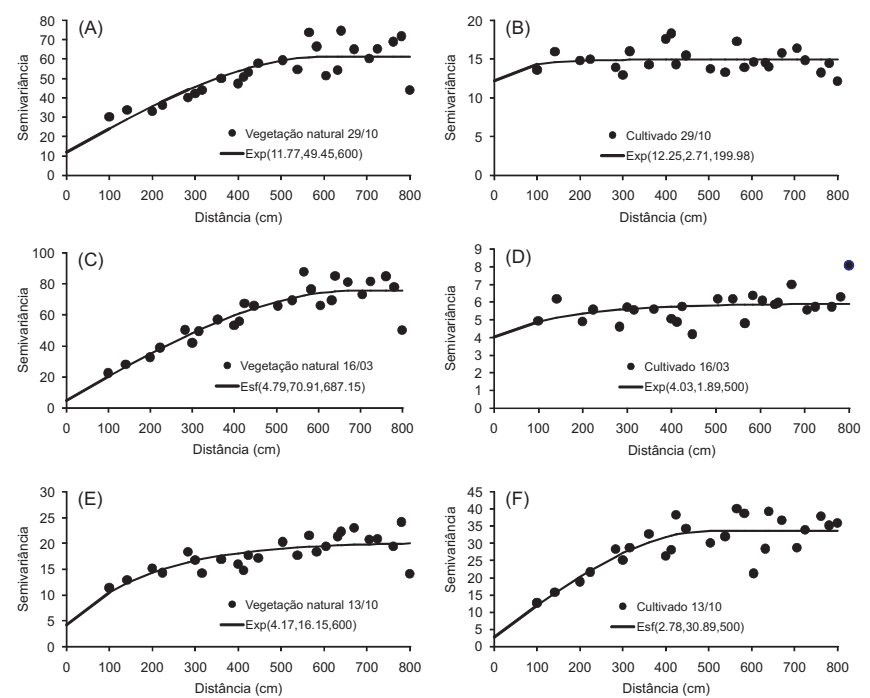

Figura 4. Semivariogramas para teor de água nas duas condições de uso e para as três datas de amostragem: a) Parcela com vegetação natural amostrada em 29/10/ 1993; b) Parcela cultivada amostrada em 29/10/1993; c) Parcela com vegetação natural amostrada em 16/3/ 1994; d) Parcela cultivada amostrada em 16/03/1994; e) Parcela com vegetação natural amostrada em 13/10/ 1994; f) Parcela cultivada amostrada em 13/10/1994. 
Desta maneira, mesmo sendo as duas parcelas adjacentes, o comportamento em termos de distribuição espacial do teor de água no solo é bastante distinto. Por outro lado, nos semivariogramas para os teores de água no solo da parcela sob vegetação natural, observou-se dependência espacial para todas elas, indistintamente. As duas amostragens efetuadas no outono (29/10/93 e 13/10/94) tiveram efeitos pepita maiores e alcances menores do que a parcela amostrada no fim do inverno (16/3/94). Na parcela sob vegetação natural, amostrada em 16/3/ 94, notou-se um semivariograma esférico com o menor efeito pepita de todas as amostragens e com o maior alcance de todos. O menor efeito pepita significa que o teor de água do solo em 16/3/94 tinha maior continuidade na pequena distância e o maior alcance significa que a semelhança entre vizinhos vai até distâncias maiores do que as outras amostragens.

Na tabela 4, pode-se observar pelos modelos matemáticos dos semivariogramas que a dependência espacial tem comportamentos ligeiramente diferentes para os dois usos. Nas duas parcelas, o efeito pepita foi pequeno (menor que 5) para umidade alta em março de 1994. Porém em outubro, na parcela sob vegetação natural, a amostragem com maior alcance e menor efeito pepita foi a parcela com maior média de teor de água, e para a parcela cultivada, ocorreu exatamente o contrário. Acredita-se que a distribuição de vegetação na parcela com vegetação natural seja a principal responsável pelos resultados anotados, pois pode interferir sobre a incidência da distribuição espacial das precipitações sobre a área de estudo, bem como também sobre as perdas de água do solo para a atmosfera. Também é possível que o cultivo do solo possa ter causado alterações na distribuição espacial da condutividade hidráulica, interferindo, assim na maneira como o solo adquire ou perde teor de água. Bouma e Hole (1971) relatam um decréscimo na condutividade hidráulica de uma parcela cultivada em relação ao solo virgem causado por acréscimos na densidade do solo e decréscimos no teor de matéria orgânica. VIEIRA et al. (1988) observaram variabilidade espacial diferente para teor de água do solo e para condutividade hidráulica causada por variações na textura da camada superficial do solo.

Tabela 4. Parâmetros de ajuste do semivariograma para o teor de água nas duas condições de uso e nas diferentes datas

\begin{tabular}{|c|c|c|c|c|c|c|}
\hline Variável & Modelo & $\mathrm{C}_{0}$ & $\mathrm{C}_{1}$ & a & $\mathrm{r}^{2}$ & RMSE \\
\hline \multicolumn{7}{|c|}{ Vegetação natural } \\
\hline $29 / 10 / 93$ & Esférico & 11,77 & 49,45 & 600,0 & 0,7053 & 5,59 \\
\hline $16 / 03 / 94$ & Esférico & 4,79 & 70,91 & 687,2 & 0,8274 & 5,37 \\
\hline $13 / 10 / 94$ & Exponencial & 4,17 & 16,15 & 600,0 & 0,5601 & 1,81 \\
\hline \multicolumn{7}{|c|}{ Cultivado } \\
\hline $29 / 10 / 93$ & Exponencial & 12,25 & 2,71 & 199,98 & 0,0032 & 1,36 \\
\hline $16 / 03 / 94$ & Exponencial & 4,03 & 1,89 & 500,00 & 0,1049 & 0,62 \\
\hline $13 / 10 / 94$ & Esférico & 2,77 & 30,89 & 500,00 & 0,6689 & 4,30 \\
\hline
\end{tabular}

$\mathrm{C}_{0}$ : efeito pepita; $\mathrm{C}_{1}$ : variancia estrutural; a: alcance $(\mathrm{m}) ; \mathrm{r}^{2}$ : coeficiente de correlação; RMSE: desvio quadrático médio relativo.

Pela análise dos semivariogramas escalonados do conteúdo de água no solo (Figura 5) verifica-se que, para a parcela com cultivo, as amostragens realizadas em $29 / 10 / 94$ e 16/3/94 tinham similaridade da variabilidade espacial; para a amostragem realizada em 13/10/94, os dados estavam mais dispersos, portanto, com variabilidade espacial diferente. Tiмm et al. (2006) ressaltam que as maiores diferenças entre os padrões de variabilidade do conteúdo de água no solo podem ser associados a eventos de precipitação pluvial alterando a estrutura de correlação espacial para observações vizinhas. Para a área com vegetação natural, percebe-se que para as três datas de amostragem ocorre determinada semelhança entre o padrão de variabilidade espacial do semivariograma escalonado, indicando maior homogeneidade dos dados para a área de estudo.
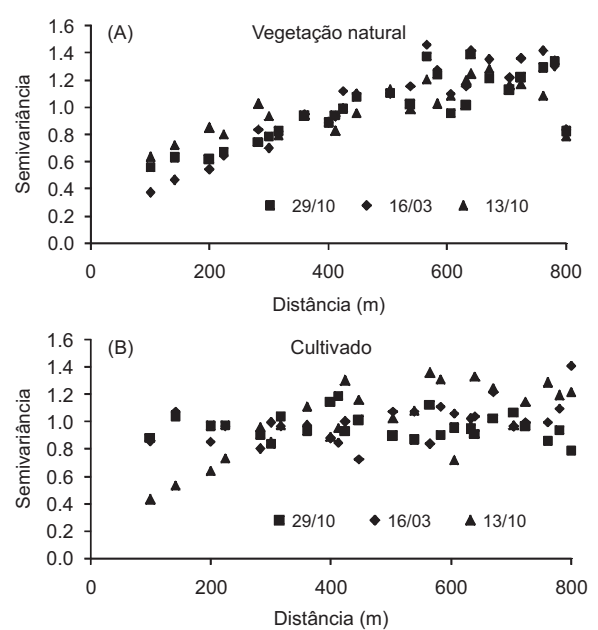

Figura 5. Semivariogramas escalonados para as duas condições de uso e nas diferentes datas de amostragem. 

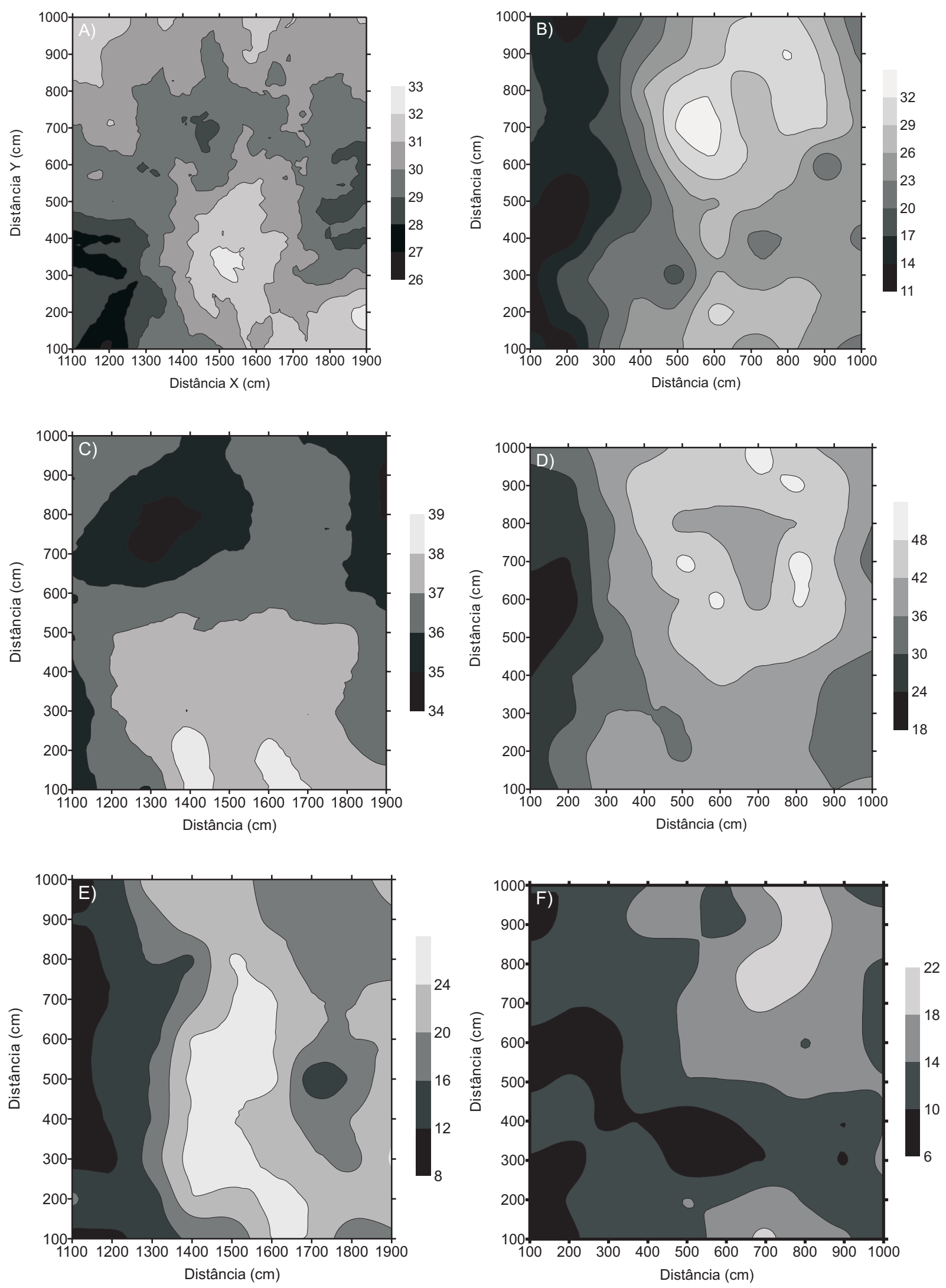

Figura 6. Mapas para o teor de água do solo nas duas condições de uso e nas três datas amostradas: a) Parcela cultivada amostrada em 29/10/1993; b) Parcela com vegetação natural amostrada em 29/10/1993; c) Parcela cultivada amostrada em 16/3/1994; d) Parcela com vegetação natural amostrada em 16/3/1994; e) Parcela cultivada amostrada em 13/ 10/1994; f) Parcela com vegetação natural amostrada em 13/10/1994. 
Os mapas obtidos por krigagem para teor de água do solo para as duas parcelas adjacentes (Figura 6) demonstram que para a amostragem realizada em 29/10/93 (Figuras 6a, b) e que, mesmo sendo adjacentes, nestas duas parcelas houve uma distribuição espacial de teor de água bastante diferente, além de valores absolutos bastante diferentes para esta data. Na parcela sob cultivo, ocorreu certo paralelismo entre linhas de contorno na direção vertical, conforme se pode verificar no mapa da figura 6a. CATTLE et al. (1994) verificaram grande decréscimo da heterogeneidade de algumas propriedades do solo em parcelas cultivadas, quando comparadas a parcelas adjacentes de solo virgem. PAZ GonZÁlez et al. (2000), estudando a variabilidade espacial das propriedades químicas destas mesmas duas parcelas, descrevem que ocorre uma homogeneização do solo causada pelo seu uso agrícola, inclusive com aumento significativo na quantidade de cascalho devido ao preparo do solo.

Nos mapas referentes às três amostragens da parcela sob vegetação natural (Figuras 6b, d, f) constata-se que existiu alguma semelhança na entre elas, em particular para as amostragens efetuadas no outono, em 29/10/93 (Figura 6b) e para 13/10/94 (Figura 6f), datas nas quais o teor de água do solo foi menor. Essas pequenas semelhanças podem ser notadas apesar de não poder se observar o paralelismo com maior evidencia entre contornos (indicando diferenças em relação à parcela sob cultivo). Nota-se também, que os semivariogramas correspondentes a estas datas (Figuras 4a e 4e) tiveram valores de alcance distintos, justificando as maiores diferenças entre os mapas de variabilidade espacial.

\section{CONCLUSÕES}

1. O uso do solo com culturas anuais altera a distribuição espacial do teor de água e por consequência sua estabilidade temporal.

2. O teor médio de água no solo tem relação inversa com a dependência espacial, ou seja, quanto maior o teor de água menor a dependência espacial.

3. O espaçamento de $1 \mathrm{~m}$ entre amostras é suficiente para caracterizar variabilidade espacial e a estabilidade temporal do teor de água para o solo com vegetação natural. Para o solo da parcela cultivada, este espaçamento foi insuficiente para a caracterização adequada da variabilidade para épocas úmidas.

\section{AGRADECIMENTO}

O primeiro autor agradece à FAPESP (Processo n. ${ }^{\circ}$ 97/12848-9) o auxílio financeiro para o desenvolvimento da pesquisa.

\section{REFERÊNCIAS}

BOUMA, J.; HOLE, F.D. Soil structure and hydraulic conductivity of adjacent virgin and cultivated pedons at two sites: A Typic Argiudoll (silt loam) and a Typic Eutrochrept (clay). Soil Science Society of America Proceeding, v.35, p.316-319, 1971.

CATTLE, S. R.; KOPPI, A. J.; MCBRATNEY, A. B. The effect of cultivation on the properties of a Rhodoxeralf from the wheat/sheep belt of New South Wales. Geoderma, v.63, p.215-225, 1994.

DEMATTÊ, J.L.I. Manejo e conservação de solos, na cultura da cana. Visão Agrícola, v.1, p.8-17, 2004.

FAO. World reference base for soil resources. Roma, 1998. 88p.

GOLDEN SOFTWARE. SURFER for windows. Realese 7.0. Contouring and 3D surface mapping for scientist's engineers. User's guide. New York: Golden Software, 1999. 619p.

GONÇALVES, A.C.A.; FOLEGATTI, M.V.; SILVA, A. P. Estabilidade temporal da distribuição espacial da umidade do solo em área irrigada por pivô central. Revista Brasileira de Ciência do Solo, v.23, p.155-164, 1999.

GONZÁLEZ GARCIA, M.A. Propriedades hidrodinamicas en la zona non saturada en relación a processos hidrologicos. 1998. 228f. Tese (Doutorado) - Universidad de Santiago de Compostela, Lugo.

JOURNEL, A.G.; HUIJBREGTS, Ch.J. Mining geostatistics. London: Academic Press, 1978. 600p.

MACHADO, R.F.; BARROS, A.C.S.A.;ZIMMER, P.B.; AMARAL, A.S. Reflexos do mecanismo de ação de herbicidas na qualidade fisiológica de sementes e na atividade enzimática em plântulas de arroz. Revista Brasileira de Sementes, v.23, p.151-160, 2006.

MCBRATNEY, A.B. On variation, uncertainty and informatics in soil management. Australian Journal of Soil Research, v.30, p.913-935, 1992.

MUSY, A.; SOUTTER, M. Physique du sol. Lausanne: Presses Polytechniques et Universitaires Romandes, 1991. 335p.

PAZ-GONZÁLEZ, A.; VIEIRA, S.R.; TABOADA CASTRO, M.T. The effect of cultivation on the variability of selected properties of an umbric horizon. Geoderma, v.97, p.273-292, 2000.

TABOADA CASTRO, M. T.; GONZÁLEZ GARCIA, M. A.; PAZ GONZÁLEZ, A. Efecto del cultivo convencional sobre la diversidad de las propriedades del suelo. In: BIENAL DA REAL SOCIEDAD ESPAÑOLA DE HISTORIA NATURAL, 12., Madrid, 1996. Bienal. Madrid: 1996. p.:451-454. 
TIMM, L.C.; PIRES, L.F.; ROVERATTI, R.; ARTHUR, R.C.J.; REICHARDT, K.; OLIVEIRA, J.C.M.; BACCHI, O.O.S. Field spatial and temporal patterns of soil water content and bulk density changes. Scientia Agricola, v.63, p.55-64, 2006.

TOPP, G.C.; DAVIS, J.L. Measurement of soil water content using time domain reflectometry (TDR): a field evaluation. Soil Science Society of America Journal, v.49, p.574-582, 1985.

VACHAUD, G.; PASSERAT DE SILANE, A.; BALABANIS, P.; VAUCLIN, M. Temporal stability of spatially measured soil water probability density function. Soil Science Society of America Journal., v.49, p.822-827, 1985.

VIEIRA, S.R. Uso de geoestatística em estudos de variabilidade espacial de propriedades do solo. In: NOVAIS,R.F. (Ed.). Tópicos em Ciência do Solo. Viçosa: Sociedade Brasileira de Ciência do Solo, 2000. p.1-54.

VIEIRA, S.R.; GUIMARÃES, E.C.; DECHEN, S.C.F.; DE MARIA, I.C.; ROCHETE, P.; TOPP, G.C.; ZEBCHUK, W. Analisando simultaneamente a variabilidade espacial e temporal usando semivariogramas tridimensionais. In: SOLO-SUELO 96, Águas de Lindóia. Resumos... Campinas: Sociedade Brasileira de Ciência do Solo, 1996.

VIEIRA, S.R.; HATFIELD, J.L.; NIELSEN, D.R.; BIGGAR, J.W. Geostatistical theory and application to variability of some agronomical properties. Hilgardia, v.51, p.1-75, 1983.

VIEIRA, S.R.; LOMBARDI NETO, F.; BURROWS, I.T. Mapeamento da chuva diária máxima provável para o Estado de São Paulo. Revista Brasileira de Ciência do Solo, v.15, p.93-98, 1991.

VIEIRA, S.R.; MILLETE, J.; TOPP, G.C.; REYNOLDS, W.D. Handbook for geoestatistical analysis of variability in soil and climate data. In: ALVAREZ, V.V.H.; SCHAEFER, C.E.G.R.; BARROS, N.F.; MELLO, J.W.V.; COSTA, J.M. Tópicos em Ciência do Solo. Viçosa: Sociedade Brasileira de Ciência do Solo, 2002. v.2, p.1-45.

VIEIRA, S.R.; NIELSEN, D.R.; BIGGAR, J.W. Spatial variability of field-measured infiltration rate. Soil Science Society of America Journal., v.45, p.1040-1048, 1981.

VIEIRA, S.R.; NIELSEN, D.R.; BIGGAR, J.W.; TILLOTSON, P.M. The Scaling of semivariograms and the kriging estimation. Revista Brasileira de Ciência do Solo, v.21, p.525-533, 1997.

VIEIRA, S.R.; REYNOLDS, W.D.; TOPP, G.C. Spatial variability of hydraulic properties in a highly structured clay soil. In: VALIDATION OF FLOW AND TRANSPORT MODELS FOR THE UNSATURATED ZONE, 1988. Ruidoso. Conference Proceedings... Ruidoso, Novo Mexico: Department of Agronomy and Horticulture, New Mexico State University, 1988. p.471-483. 